\title{
ANCIENT RITUALS AND THEIR PLACE IN THE MODERN WORLD: CULTURE, MASCULINITY AND THE KILLING OF BULLS - PART TWO
}

\author{
Stephen Allister Peté \\ BA LLB LLM MPhil \\ Associate Professor, Howard College Campus \\ University of KwaZulu-Natal, Durban \\ Angela Diane Crocker \\ BSC LLB LLM \\ Lecturer in Law, Howard College Campus \\ University of KwaZulu-Natal, Durban \\ Attorney of the High Court of South Africa
}

SUMMARY

Each year in KwaZulu-Natal, South Africa, a ceremony is held by the Zulu people in honour of the "first fruits". A certain part of what is known as the Ukweshwama ceremony involves the ritual killing of a bull by young Zulu warriors with their bare hands. The ritual is opposed by certain animal rights campaigners, who believe it is cruel to the animal which is sacrificed. A highly polarized debate has arisen between those opposed to any form of cruelty to animals on the one hand, and those seeking to defend ancient cultural practices on the other. The purpose of this article is to explore whether or not ancient rituals such as the ritual bull-killing at the Ukweshwama ceremony have a place in the modern world, and to interrogate the implications of the dispute which has arisen for the development of South Africa's constitutional democracy. The article is in two parts. Part One provides a brief synopsis of the importance of cattle within traditional Zulu culture and traces the public controversy surrounding the bull-killing ritual in KwaZulu-Natal. It also examines the legal arguments put before court on the issue, and discusses the origins in antiquity of certain of the main myths and rituals concerning bulls and bullkilling. Part Two compares and contrasts the respective controversies surrounding the Ukweshwama bull-killing ritual on the one hand, and Spanish bullfighting on the other. It also examines the wide range of positions adopted by philosophers and legal scholars vis-a-vis difficult questions of animal rights and cruelty to animals. The two sides of the argument are weighed up and tentative conclusions are reached. 


\section{$1 \quad$ INTRODUCTION}

In Part One of this article the issue of ancient rituals and their place in the modern world was raised in the context of the recent controversy surrounding the ritual bull-killing which forms part of the Ukweshwama first fruits ceremony of the Zulu people, which is celebrated each year in KwaZulu-Natal, South Africa. The article began with a brief discussion of the importance of cattle within traditional Zulu culture. We then described and discussed the recent public controversy surrounding the annual bull-killing ritual in KwaZulu-Natal, as well as the legal battle which took place over the issue in 2009 and 2010. Thereafter, in order to situate the Zulu Ukweshwama ceremony and its bull-killing ritual within a global and historical context, Part One of the article dealt with the origins in antiquity of certain of the main myths and rituals concerning bulls and bull-killing.

In part two of this article, we shall begin by comparing and contrasting the respective controversies surrounding the Ukweshwama ritual bull-killing ceremony on the one hand, with the controversies surrounding Spanish bullfighting on the other. In this way we hope to situate the controversy which has arisen around the Zulu bull-killing ritual, within a contemporary global context. In the course of this discussion, we hope to provide a sense of precisely what is at stake for those on the "cultural rights" side of the argument, between those supporting "cultural rights" on the one hand, and those in favour of "animal rights" on the other. The "animal rights" side of the argument will then be examined in order to reveal the wide range of positions adopted by philosophers and legal scholars vis-á-vis the difficult question of animal rights. Once again, it is hoped that this discussion will reveal what is at stake for those on that particular side of the argument. The article will conclude by weighing up the two sides of the argument and reaching certain tentative conclusions as to the manner in which the controversy surrounding ritual bull-killing in KwaZulu-Natal may best be resolved.

\section{BULL-KILLING RITUALS WITHIN A CON- TEMPORARY GLOBAL CONTEXT - PARALLELS WITH SPANISH BULLFIGHTING}

The controversies surrounding Spanish bullfighting provide a contemporary point of reference with which to compare the Ukweshwama bull-killing ritual. Bullfighting is an ancient practice in Spain. According to $\mathrm{JL}$ Acquaroni, it began as a sport and type of amusement for aristocrats, and he points out that "in the XVIth and XVIlth Centuries ... bullfights were organized in the public squares, as an established, traditional event, on the occasion of military victories, the birth and marriage of princes or religious solemnities presided over by the King and Queen". Nobility used the sport to show their proficiency on horseback and it was considered good training for war. ${ }^{2}$ As time went on, bullfighting began to include common people, whose daring

\footnotetext{
Acquaroni Bulls and Bullfighting (1961) 13.

Acquaroni Bulls and Bullfighting 54.
} 
exploits in the ring included killing bulls on foot with a single sword. This popularized and commercialized the sport, which gradually evolved from a type of hunt to a form of art. ${ }^{3}$

The idea that bullfighting is a form of art is illustrated by Charteris, who provides the following vivid description of the ideal for which matadors in the bullring are said to strive:

"[The killing of the bull by the matador] must be done valiantly, artistically, gracefully, and according to a fixed and timed procedure, so that the tempo of the fight rises through a crescendo like great music to the supreme emotion of the last moments ... What [the matador] should be doing is performing his task with so much grace and beauty that you are not conscious of the practical end of it ... You will see man and bull, who have been gyrating together like partners in a dance, suddenly welded together, the man merged with the bull, bound to the bull by the sword, with the steel vanished altogether and only the man's hand grasping the hilt of the sword on the crest of the bull's back, the matador with the bull's horns under him and his body bowed over the bull; and it will be something that you will never forget."

Rimas and Fraser argue that even though this form of "art" may repel or offend some, its aesthetic principles and capacity to sway the emotions of an audience, cannot be denied:

"Even the most disgusted witness to a bullfight must agree that the spectacle is as aesthetically principled as Swan Lake. What art cannot do is leave its audience unmoved."

In a similar vein, Charteris, maintains that:

"Bullfighting is not a sport, ${ }^{6}$ and you can't compare it with one: the enthusiasm of any sport fan when his champion does well is on an utterly different plane from the emotion of bullfighting. Bullfighting, whether you like it or not, whether you approve of it or not, is an art, like painting or music, and you can only judge it as an art: its emotion is spiritual, and it touches depths which can only be compared with the depths that are touched in a man who knows and understands and loves music by a symphony orchestra under a great conductor."

3 Acquaroni Bulls and Bullfighting 19 and 55.

4 Charteris Juan Belmonte Killer of Bulls: The Autobiography of a Matador (1937) 5-20.

5 Rimas and Fraser Beef: The Untold Story of How Milk, Meat, and Muscle Shaped the World (2008) 29.

6 It is interesting to note Burnstyn's comments on spectator involvement in the ritualsspectator sport: "When moments of primal physical intensity are socially shared through the performance of physical ritual, the athlete's intrinsic pleasure of bodily performance and his sacrificial pain, if pain has been involved, are crowned and embellished by a sense of belonging. The crowd feels a similar pleasure and pain and, if victory is achieved, a feeling of representation and affirmation. At that moment, athletes and spectators are transcendentally united in the celebration of their champions - symbolic figures who represent the strength, well-being, and fare of their communities." Burstyn, The Rites of Men: Manhood, Politics, and the Culture of Sport (1999) 24.

7 Charteris Juan Belmonte Killer of Bulls: The Autobiography of a Matador(1937) 2-3. 
Ernest Hemingway, on the other hand, regarded the death of the bull in a bullfight as a tragedy, an unequal match played out by man and bull, involving "danger for the man but certain death for the animal."

Of greater relevance to the question at issue in this article, however, is that it is interesting to note that scholarly commentators do not simply regard bullfighting as a fight, or a competitive sport, or a game, or a theatrical show. They also link it to a form of "ritual sacrifice" which forms "part of Spanish popular Catholicism ..." ${ }^{9}$ Pitt-Rivers points out that "just about half the bulls immolated in the corridas of Spain are sacrificed in honour of the Virgin Mary, as part of the celebration of a religious festival; the calendar of bullfights is the religious calendar." ${ }^{\prime 10}$ Winterson, who refuses to regard bullfighting as a form of art, agrees with Pitt-Rivers that the practice is linked strongly to ancient religious practices:

"[The] levels of cruelty and violence [of a bullfight] prevent it from being an art ... an art cannot exceed certain parameters of damage ... it cannot cause death. I feel that the corrida is still very close to its origins in religion, that it is a religious ritual in a state of slow transition."1

What is clear is that bullfighting is deeply ingrained within Spanish culture. Pitt-Rivers points out that the practice enjoys significant support among the Spanish people and states that: "The only constant ally of the bullfight has been the Spanish people who cannot conceive of celebrating anything without sacrificing bovines, any more than the Muslim (or Judaeic) peoples can do so without sacrificing ovines." ${ }^{12}$ But this does not mean that Spanish culture is static and immutable. Despite significant levels of support for bullfighting, it is clear that the practice is deeply contested within Spain and around the world. There are indications that, during recent years, the

8 Hemingway Death in the Afternoon (1932) 19.

9 Pitt-Rivers "The Spanish Bull-fight" August 1993 9(4) Anthropology Today 11. Pitt-Rivers points out that: "The bull-fight, also called lidia (struggle) in Spanish, is not really a fight at all; the bull cannot win, for even if he kills or disables the matador, one of the other matadors (they are usually three) must replace him and complete the rite. And if he cannot be killed by a bullfighter he is killed by a butcher, the same evening. He can only survive if the public demands of the president (whose principal function is to be the mouthpiece of the public) that the bull be 'pardoned' on account of his exceptional courage and 'nobility', that is to say because he has embodied to perfection the values that the cult of the bull is intended to promote."

10 Pitt-Rivers August 1993 9(4) Anthropology Today 11 and 12. According to Pitt-Rivers: "The bull-fight takes place always after, never before, the Mass, in the afternoon ... After the purification of the sacrifice of the Lamb the sacrifice of the bull restores to grace the mores of everyday life, releasing the faithful from an excess of sanctity, a too literal subjection to the Beatitudes, which renders the practical conduct of daily affairs somewhat difficult, for if all were to be 'poor in spirit' and 'meek' and turn the other cheek when struck, there could be no exercise of authority, no defence of one's rights, the wicked would have it all their own way and the social structure would collapse. Therefore, after the sacrifice of the Mass ... there follows the 'fiesta brava', as the corrida is called, to restore the worldly order, a counter-rite to the first ... it is ... in no way an attempt to annul the purifying message of the Mass, but rather to complement it and integrate it into the practical sphere of daily life."

11 Kennedy On Bullfighting (2000) 86-87.

12 Pitt-Rivers August 1993 9(4) Anthropology Today 13. 
popularity of bullfighting has been declining among Spaniards. ${ }^{13}$ Yet it remains big business. From bull breeders to bullfighters' assistants, the bullfighting industry employs around 200000 people and has an annual turnover of about $€ 1.5$ billion. ${ }^{14}$ According to Rimas and Fraser, the number of spectators who attend bullfights numbers around forty-five million, and they attend around two thousand bullfights. These bullfights support two hundred thousand jobs and fifteen hundred working bull farms. ${ }^{15}$ Furthermore, well known matadors are able to earn up to 180000 euros per appearance. ${ }^{16}$

There are clear parallels between the Ukweshwama bull-killing ritual, which is fiercely opposed by animal-rights groups, and Spanish bullfighting, which is similarly targeted by such groups. Both practices have ancient premodern roots and are deeply embedded in local culture and tradition; both are linked to spiritual and religious traditions and values, and lie at the heart of particular cultural identities; both speak to issues of honour and masculinity; and, finally, both are subject to fierce opposition from groups who operate within a completely separate discourse, which postulates an alternative view of the relationship between humans and nature. Before moving on to the animal-rights side of the debate, it is useful to focus on two of the abovementioned sets of parallels between the Ukweshwama bullkilling ritual and Spanish bullfighting, in order to illustrate the fairly close links between these two cultural practices. The first set of parallels concerns issues of masculinity and fertility, and the second concerns the respective political interests which may be seen to warp the debate in each case.

As far as masculinity and fertility are concerned, we have mentioned earlier that, in killing the bull during the Ukweshwama ceremony, it is believed that the young Zulu warriors gain its strength, which is then symbolically transferred to the King on his emergence from seclusion. The power of the young warriors in overcoming the bull is symbolic of the power that the King wields over the Zulu nation. It is clear, therefore, that the Zulu bull-killing ritual is strongly linked to issues of masculine strength, leadership and fertility. This resonates strongly with Spanish bullfighting. In relation to the issue of bullfighting and masculinity, Pitt-Rivers states that: "The bull who

13 In 2007 statistics revealed that $72 \%$ of Spaniards had no interest in the sport and that the modern bullfighting public consists mainly of elderly men, with $82 \%$ of young people and $78.5 \%$ of women not showing any interest in the spectacle. See Tarvainen "Spanish Bullfighting Slowly Bleeding to Death" 5 January 2007 Main and Guardian Online www.mg.co.za/article/2007-01-05-spanish-bullfighting-slowly-bleeding-to-death.

14 Sinikka Tarvainen 5 January 2007 Main and Guardian Online www.mg.co.za/article/2007-0105-spanish-bullfighting-slowly-bleeding-to-death.

15 Rimas and Fraser Beef: The Untold Story of How Milk, Meat, and Muscle Shaped the World (2008) 34, quoting De la Cal "El Toro No Es Tradicion, Es Negocio" 24 December 2006 El Mundo.

16 See Rimas and Fraser Beef: The Untold Story of How Milk, Meat, and Muscle Shaped the World (2008) 34. It is interesting to note that in 2010, 1.5 million people attended the annual bull-running festival in Pamplona, northern Spain. With between 200 and 300 participants being injured each year organizers are continually increasing safety measures. In 2011 organizers have made a free iPhone app available in English, which helps revellers assess their safety by asking them about their drinking habits and amount of sleep that they've had. "Four Hurt in Bull Run as San Fermin Fiesta Begins" 8 July 2011 The Mercury 8. 
has demonstrated his ability to personify the values he was created to represent - aggression, courage, straight-forwardness, 'nobility', the ideal masculine virtues - is treated with great respect: gentlemen stand out of respect to honour him when he is towed round the ring to receive applause." ${ }^{17}$ As far as Spanish bullfighting and fertility are concerned, PittRivers states as follows:

"[S]ince this is also a fertility rite the bull represents the indefatigable capacity for copulation which is credited to animals ... The bull combines, as symbol, both the male moral virtues, but also, essential to a fertility rite, the animal virtue necessary to ensure fertility. It is the combination of moral human virtues and the physical capacity of animals, placing both under the aegis of the Virgin, Christ or the saints, that gives the corrida its profound meaning."

Moving to the political overtones which tend to colour these debates, it seems clear that efforts to ban bullfighting are often bound up with political objectives. A good example is the recent campaign against bullfighting in the Catalonian region of Spain. The practice was finally outlawed by the regional parliament of Catalonia on 28 July 2010. According to The Economist the act of banning bullfighting was "a bit like a German state banning wurst or a French region condemning those pesky berets." ${ }^{19}$ The ban thus constituted a powerful political statement. It may be argued that the push for a ban on bullfighting in Catalonia formed part of a political agenda on the part of the Catalonians to shape an identity independent of Spain, rather than arising purely out of concern for animal welfare. Rejecting Spain's national pastime in Catalonia may, perhaps, have served to distance the Catalonians from the rest of the country, helping them to shape a distinct political identity. ${ }^{20}$ Similarly it may, perhaps, be argued that the reintroduction of the Ukweshwama bull-killing ritual serves to reinforce Zulu pride, battered by centuries of colonialism and apartheid. The protection of cultural practices within a country newly liberated from the yoke of a dictatorial and intolerant regime is bound to be a politically sensitive issue. The political and legal tightrope between constitutionally protected cultural rights on the one hand, and countervailing rights which may also enjoy constitutional protection on the other, is not easy to negotiate. Noluthando Ntlokwana, assistant director of the Centre for Constitutional Rights, commented as follows on the issue of overlapping customary and constitutional rights:

"Recognising our rich cultural diversity, the Constitution provides for and protects the freedom to participate in the cultural life of one's choice, but only in a manner that is consistent with it. It accords parity of esteem to all our cultures and enjoins the courts to interpret and develop customary law in a manner that promotes the spirit, purport and objects of the Bill of Rights."

\footnotetext{
17 Pitt-Rivers August 1993 9(4) Anthropology Today 12.

Ibid.

"Bullfighting in Catalonia: The Land of the Ban" 31 July 2010 The Economist 20.

Ibid.

21 Ntlokwana "Bound by the Bill of Rights" Mail and Guardian Online 2010-01-20 www.mg.co.za.
} 
For Ntlokwana, the High Court case involving the Ukweshwama bull-killing ritual discussed in Part One of this article, illustrated the dangers of cultural intolerance:

"The court held that the applicant's uncritical acceptance of rumours about the true practice was symptomatic of an intolerance of cultural diversity ... Viewed in a historic perspective, it was indicative of a historical desire to inflict mainstream cultures of Western society on African cultures. This attitude was premised on a misguided belief that the applicant had a right to interfere with the religious and cultural practices of others that they found intolerable to their own beliefs."

The political sensitivity of this matter is clear in the statement quoted above and is further illustrated by the following statement of the ruling African National Congress:

"Apartheid system sought to relegate the cultural and traditional practices of the majority South Africans to the humiliating levels of lowliness. For centuries Black people, Africans in particular, were dictated upon how to conduct their cultures. A foreign way of living was imposed upon them. The enactment of progressive legislations since 1994 has sought to cleanse our society of the centuries-old legacy of apartheid and colonialism and ensured that any remaining practice that belonged to the old order does not creep back into the current dispensation in any form or shape. For this reason, the Commission ${ }^{23}$ is gravely concerned at the approach and the tone taken by those opposed to some of the cultural and traditional practices our people are practicing."

On the other side of the coin, of course, are those who regard the particular ritual in question as inherently cruel and outdated, having no place within a progressive, constitutional democracy. Having noted the political dimensions of the debate, let us now turn to the arguments which may be advanced from the side of those who may be expected to be opposed to the ritual - those against any form of cruelty to animals, those who support "animal liberation" and those who argue for animal rights.

22 Ibid. Ntlokwana goes further to suggest that issues involving opposing views on cultural practices should be dealt with by forums such as the Congress of Traditional Leaders of South Africa (Contralesa). She argues that since members of Contralesa are themselves immersed in ancestral spirits, they are better able to develop customs such as ukweshwama, which are complex in nature and in most instances involve invoking these spirits. These practices can then be developed in such a way that they "pass constitutional muster while retaining the core of the custom". This sentiment was reiterated in a statement by a spokesperson for the African National Congress (ANC) concerning the controversy surrounding the Ukweshwama festival. The view of the ANC, as articulated by the spokesperson, was that the animal-rights group had used the incorrect forum to address their concerns and that, instead of taking the matter to the courts, the issues should have been discussed with a constitutional platform such as the Commission for the Promotion and Protection of the Rights of Cultural, Religious and Linguistic Communities (CRL Commission). In this forum, the ANC spokesperson argued, "diverse cultural practices can be discussed to achieve common ground and tolerance" and "perceived cultural intolerance" could be avoided. See Creamer Media Reporter "ANC: Statement by Mathole Motshekga, African National Congress Spokesperson, On Bull Killing (01/12/2009)" www.polity.org.za accessed 2010-08-24.

23 African National Congress's Commission on Religious and Traditional Affairs.

${ }^{24}$ Creamer Media Reporter, see fn 22 above. 


\section{UKWESHWAMA BULL-KILLING - POTENTIAL ARGUMENTS AGAINST}

\section{The expanding circle of moral concern}

It is impossible, in a brief article such as this, to do justice to the wide range of complex philosophical and legal arguments which may be put forward in defence of the principle that any form of cruelty to animals is morally and legally indefensible.

We may begin, perhaps, by looking at legal rights and focusing only on excluded groups within the human community over time. It is worth noting that, over the centuries, legal rights have been extended gradually to include marginalized groups (for example, women, children and slaves) which did not always enjoy such rights. Pushing the boundary even further, legal rights have even been extended to inanimate objects such as trusts and companies. Furthermore, from as early as the 1970s, legal philosophers such as Christopher Stone have promoted the idea of extending legal rights even further to non-human animals, and even to the environment itself. ${ }^{25}$ In philosophical terms this evolution in legal thinking may, perhaps, be explained as the result of a gradual expansion in the "circle of moral concern" within most societies.

Those who argue on behalf of animals and the environment, generally regard the expansion of the "circle of moral concern" to encompass all humans, as only a first step. Depending upon the specific philosophical position taken, they may insist that the "circle" ought to be expanded beyond human beings, so that it comes to encompass all sentient beings. They may argue, for example, that sentient beings have the capacity to suffer, and that all unnecessary suffering is morally wrong. Other thinkers may submit that the expansion of the "circle of moral concern" need not stop at this point. They may want to expand the "circle" further so as to encompass all living things. They may motivate in favour of this further expansion on the grounds that all life has intrinsic value and that it is, therefore, morally wrong to harm or kill any living thing, unless there is a good moral reason for doing so. Finally, there may be those who would argue in favour of yet another expansion of the "circle of moral concern". For example, in line with the thinking of "deep ecologists" such as Arne Naess, there are those who maintain that the environment itself has intrinsic value, making it morally wrong to deform or destroy any part of the environment (one could, perhaps, think of a mountain or valley which has not yet been altered by humans) without a good moral reason for doing so.

Let us restrict our discussion to what concerns us in this article expanding the circle of moral concern just far enough to include sentient animals such as bulls. From the human perspective, a concern which may

25 Stone Should Trees Have Legal Standing?: Law, Morality, and the Environment - Third Edition (2010) 1-3. In this classic text, which was first published in 1974, Stone argues that rights should be conferred upon natural objects in the environment, such as forests, oceans and rivers. 
arise in relation to expanding the "circle of moral concern" in this way is that it is a "one-way street". After all, only humans can be blamed (that is, held morally responsible) for cruel behaviour, since they are the only sentient beings capable of forming an intention to inflict unnecessary suffering (cruel treatment) on other sentient beings (although certain humans such as very young children and severely mentally disabled humans are not capable of forming such an intention). In other words, only humans (excluding those humans who are incapable of rational thought, that is, who are not morally "autonomous") are capable of acting "cruelly" in a moral sense, and must pay the price for being the only sentient animal capable of moral reason, by accepting the responsibility not to treat any sentient being or beings (including other humans) in a cruel manner. Is this unfair to humans? Should the fact that non-human sentient animals are not autonomous - that is, are unable to apply reason to moral issues and act accordingly - not affect their eligibility to form part of a moral community? In simple terms, if a sentient non-human animal cannot be held morally responsible for its actions may it, nevertheless, lay claim to membership of a moral community? Or, to put it another way, is it possible for a creature to have the rights of a member of a particular moral community, but not the responsibilities of members of that community? Of course, rights and responsibilities are reciprocal to a certain extent. If a certain member of a moral community has a right, then other members of that moral community have the responsibility to respect that right. But this does not mean that all members of the moral community carry this responsibility since, even in human communities, certain members of the community may not be in a position to respect the rights of others - for example, very young children, or people who are severely mentally challenged. In other words, you do not have to be a "moral agent" (someone with both rights and responsibilities) to form part of a moral community. It is sufficient for you to be a "moral patient" (someone who has rights but no responsibilities). Therefore, the fact that sentient animals are not autonomous, should not affect their eligibility to form part of a moral community including humans.

Even if we accept that all sentient animals form part of our circle of moral concern, as well as the contention that it is humans alone who bear moral responsibility not to inflict unnecessary suffering on (that is, not to act cruelly in respect of) any sentient being, an important question still remains: what counts as the infliction of unnecessary suffering? It cannot mean the infliction of no pain at all by humans, since it is clear that suffering forms part of the fabric of nature. The survival of one species often requires the infliction of suffering upon another species. Many would argue that human beings are clearly part of nature in this respect. ${ }^{26}$ And so we are left with having to balance human pain against the pain of species upon which we inflict suffering. This is extremely difficult. For example, what should be the moral weight of the pain experienced by humans in not being able to develop a shampoo tested on the eyes of rabbits; or in not being able to

${ }^{26}$ Alison Hills expresses a similar idea: "Should we try to efface ourselves entirely, withdrawing until we have a minimal impact on the natural world? This goal of the 'invisible man' is plainly unrealistic. The natural world is where we live; we are part of it and we cannot avoid affecting it." Hills Do Animals Have Rights? (2005) 229. 
develop a new drug for a deadly human disease tested on hundreds of primates; or in not being able to eat meat at all; or in having to pay significantly more for eggs which are "free range"; or, as in the case under discussion in this article, in not being permitted to wrestle a bull to death in accordance with an ancient ritual? On the other side of the equation, how does one measure the extent of the "pain" suffered by sentient animals of different species, since it is probable that different species experience pain differently? For example, what should be the moral weight attached to the pain experienced by the various animals in the examples cited above? It seems beyond dispute that, in the past, the moral balance has been weighted far too heavily in favour of avoiding human pain (no matter how trivial) as opposed to avoiding animal pain (no matter how severe). As Alison Hills puts it: "It is clear that for too long we have weighted the scales enormously on our own side, allowing great harm to animals for the sake of small benefits to us ..."27

With the above as a broad introduction, we move now to a more specific focus on both the anthropocentric and non-anthropocentric arguments which may be put forward to underpin South Africa's present anti-cruelty legislation.

\section{Anthropocentric and non-anthropocentric argu- ments}

In terms of present South African legislation, cruelty (that is, the causing of unnecessary suffering) to animals is prohibited. ${ }^{28}$ In order to interpret the relevant legislative provisions properly, it is important to understand certain of the main philosophical positions which have been and may be used to justify prohibitions on cruelty to animals generally. At the outset it is useful to distinguish between anthropocentric (that is, human-centred) and nonanthropocentric (more widely centred) arguments.

The anthropocentric argument against cruelty to animals is most famously associated with the philosopher Immanuel Kant. According to Kant, animals are not moral agents and cannot form part of the moral community to which human beings, who are moral agents, belong. Although we do not owe to animals the moral duty that we owe to other human beings, however, it does not mean that we are morally permitted to treat animals cruelly. In fact, there is a moral duty on us not to treat animals cruelly, but it is a duty which is, in fact, owed to other human beings. It is argued that, if we allow cruelty to animals, people will become more sadistic and cruel in the way they treat other people. In other words, if a person is allowed to treat animals cruelly, it will encourage cruel behaviour, which may result in other humans being treated in a cruel manner. In other words, the reason that we do not permit cruelty to animals is not because animals have a similar moral status to

7 Hills Do Animals Have Rights? 229

28 See s 2(1)(a) of the Animal Protection Act 71 of 1962, which provides that any person who "ill-treats ..., infuriates, tortures or maims or cruelly beats, kicks, goads or terrifies any animal; shall ... be guilty of an offence". 
humans, but because we owe a moral duty to other humans not to encourage cruel behaviour.

How may this anthropocentric argument against cruelty to animals be interpreted within the context of the values enshrined in the South African Constitution? The human suffering which characterized South Africa's past is recognized in the Preamble to the Constitution, which states, inter alia, that: "We, the people of South Africa ... Honour those who suffered for justice and freedom in our land." The Constitution clearly envisages a move away from a past characterized by cruelty and suffering, to a future characterized by justice and freedom. This being the case it may be argued, perhaps, that human dignity, one of the founding values set out in section 1 (a) and protected in terms of section 10 of the Constitution, cannot be achieved properly in a country which does not seek to curb cruelty (that is, unnecessary suffering) in any of its forms. In other words, it may be argued that the human dignity of each and every South African is linked to a commitment on the part of our society as a whole to oppose cruel behaviour and eliminate unnecessary suffering, both on the part of humans and animals.

It is submitted that the anthropocentric arguments set out above may serve, respectively, as philosophical and constitutional justifications for the current legislation prohibiting cruelty to animals in South Africa. If this justification for the legislation is accepted, the focus then shifts to deciding precisely what constitutes "unnecessary suffering". A continuum may be said to exist: At the one end of the continuum, the proposal that great suffering on the part of an animal is justified if there is even the slightest improvement in the human good (for example, skinning an animal alive ensures a softer pelt). At the other end of the continuum, the proposal that even the slightest suffering on the part of an animal is not justified, even though a very great improvement in the human good is at stake (for example, there is a realistic prospect of curing a deadly human disease if medical testing is allowed on a single rat). It would seem that precisely where on the continuum the line is to be drawn, will be dictated by the current mores of society. In the South African context at present, even from this anthropocentric standpoint, it is submitted that a strong argument may be made in favour of drawing the line so as to reduce animal suffering to as great an extent as possible. Once again, the argument here is that South Africans may be expected to lean in favour of reducing suffering as far as possible, precisely because many South Africans have direct experience of a cruel past, characterized by much unnecessary suffering, from which they wish to distance themselves.

Many, however, would not be satisfied with the anthropocentric nature of the argument set out above, and would militate in favour of a nonanthropocentric approach. Generally speaking, those who argue from such a non-anthropocentric philosophical standpoint accord moral status, and in certain instances even assign legal rights, to non-human animals. Two of the main strands of non-anthropocentric thinking are represented by utilitarian philosophers such as Jeremy Bentham and Peter Singer on the one hand and anti-utilitarian philosophers such as Tom Regan on the other hand. From a utilitarian moral perspective, for thinkers such as Bentham and 
Singer, all suffering is evil, whether human or animal, and must be taken into account. Tom Regan argues against the utilitarian approach. He submits that those animals, both human and non-human, which qualify as "the subjects-of-a-life" (very generally speaking, creatures which are aware of their existence and have some conception of what is good and bad for their lives) possess "inherent value" and cannot be treated as mere means to achieve the greater good. In other words, non-human animals which are the subjects-of-a-life should not be treated in a cruel manner simply because doing this will benefit humans. It is important to examine the theories of these two important thinkers - Singer and Regan - in more detail:

\section{Peter Singer and the Utilitarian Argument Against Cruelty to Animals}

Peter Singer, an Australian ethicist and professor of philosophy, is the author of the well known work "Animal Liberation", and is credited with starting the animal rights movement. ${ }^{29}$ Strictly speaking, Singer does not advocate "animal rights" in the narrow sense of the term. His central starting point is inspired by the founding father of utilitarianism, Jeremy Bentham who, in a key passage in his famous work "Introduction to the Principles of Morals and Legislation", states as follows:

"The day may come when the rest of the animal creation may acquire those rights which never could have been with-holden from them but by the hand of tyranny. The French have already discovered that the blackness of the skin is no reason why a human being should be abandoned without redress to the caprice of a tormentor. It may one day come to be recognised that the number of legs, the villosity of the skin, or the termination of the os sacrum, are reasons equally insufficient for abandoning a sensitive being to the same fate. What else is it that should trace the insuperable line? Is it the faculty of reason, or perhaps the faculty of discourse? But a full-grown horse or dog is beyond comparison a more rational, as well as a more conversable animal, than an infant of a day, or a week, or even a month, old. But suppose they were otherwise, what would it avail? The question is not, Can they reason? Nor, Can they talk? But, Can they suffer?"30

From this crucial starting point - a recognition that many animals have the capacity for suffering (or, to be more accurate, a recognition that many animals have the capacity both for suffering and/or enjoyment or "happiness") - flows the utilitarian argument that the suffering of animals is to be avoided, and must be taken into moral account when benefits to humans are "purchased" at the cost of enormous suffering by certain animals. In other words, for a utilitarian such as Singer, all suffering "counts". All suffering, whether it is human suffering or animal suffering, is to be avoided. The greater the suffering, the greater should be the degree of moral

29 Singer Animal Liberation (1975, 1990 and 2002). Peter Singer's book, first published in 1975, has come to be know by many as the "Animal Rights Bible". In the book, Singer adopts a utilitarian philosophical position, in terms of which suffering, including the suffering of animals, must be minimized. Note that in an article such as this, it is not possible to provide more than the briefest of introductions to what is a complex philosophical position, which has been the subject of much scholarly debate over many years.

${ }^{30}$ Cited in Peter Singer Animal Liberation (2002) 7. 
repugnance attached to such suffering. One should not attach greater moral weight to suffering simply because such suffering is human suffering. Equal moral weight should be attached to equal degrees of suffering. According to Singer:

"If a being suffers there can be no moral justification for refusing to take that suffering into consideration. No matter what the nature of the being, the principle of equality requires that its suffering be counted equally with the like suffering - insofar as rough comparisons can be made - of any other being."

With his utilitarian focus on "suffering" on the one hand and "enjoyment/happiness" on the other, Singer is able to draw the boundary line between beings morally entitled to have their interests taken into account, and those not so entitled, at the point where a being may be said to be "sentient" (that is, in general terms, capable of suffering and/or experiencing enjoyment). Defending his particular boundary line, Singer makes use of an argument particularly interesting in the South African context:

"So the limit of sentience (using the term as a convenient if not strictly accurate shorthand for the capacity to suffer and/or experience enjoyment) is the only defensible boundary of concern for the interests of others. To mark this boundary by some other characteristic like intelligence or rationality would be to mark it in an arbitrary manner. Why not choose some other characteristic, like skin color? Racists violate the principle of equality by giving greater weight to the interests of members of their own race when there is a clash between their interests and the interests of those of another race. Sexists violate the principle of equality by favoring the interests of their own sex. Similarly, speciesists allow the interests of their own species to override the greater interests of members of other species. The pattern is identical in each case."

To a utilitarian thinker such as Singer, there is, from a moral point of view, no sharp distinction between humans and non-humans, but rather what we might refer to as a "continuum of sentience", from beings with the most basic capacities for suffering and enjoyment, to those with the most highly developed and sensitive capacities for suffering and enjoyment. ${ }^{33}$

Singer Animal Liberation (2002) 8.

Singer Animal Liberation (2002) 8-9.

${ }_{33}$ Many legal thinkers have followed in Singer's footsteps, highlighting the capacity of a being to feel pleasure and pain, as being central to moral decisions about the treatment of such being. Alison Hills, in her 2005 work Do Animals Have Rights?, is one such example. While recognizing that there are important differences between human and animal minds, in particular the fact that non-human animals are not autonomous (ie, they cannot, so far as we know, reflect on their beliefs and desires, assess whether they have good reasons to act, or change their behaviour in accordance with what they think they have most reason to do), Hills argues that it is not the capacity to be autonomous that confers moral status on a being. Rather, moral status is conferred on a being due to the fact that that being can feel pain and therefore suffer. She puts forward this argument at various points of her work: "It is hard to see how, if human pain matters morally, animal pain could not. But if it matters morally when you cause pain to animals, then animals that can feel pain must have moral status." (Hills Do Animals Have Rights? 107); and "The ground of moral status is the capacity to feel pain and pleasure. Any animals that can feel pain have moral status: it matters morally when they suffer." (Hills Do Animals Have Rights? 156); and "It matters morally what we do to animals that can feel pain: we ought not to cause them pain unnecessarily, without good reason. 
While, for Singer, pain is pain, and suffering is suffering, when it comes to killing, other factors come into play. He points out that taking the life of a being which is self-aware, has dreams of the future, and can enter into meaningful relationships with others, is not morally equivalent to taking the life of a being without such capacities: "I conclude, then, that a rejection of speciesism does not imply that all lives
are of equal worth. While self-awareness, the capacity to think ahead and
have hopes and aspirations for the future, the capacity for meaningful
relations with others and so on are not relevant to the question of inflicting
pain - since pain is pain, the being may have - these capacities are relevant
to the question of taking life. It is not arbitrary to hold that the life of a self-
aware being, capable of abstract thought, of planning for the future, of
complex acts of communication, and so on, is more valuable than the life of a
being without these capacities."

It is clear, therefore, that for Singer, although the suffering of all sentient beings counts equally, the lives of certain beings are more valuable than the lives of others. Generally speaking, therefore, if one had to choose between taking the life of a sentient human being with normal human capacities, and the life of a sentient non-human being with the normal capacities of such a being, one would choose to take the life of the latter and not the former. Singer points out that: "The preference, in normal cases, for saving a human life over the life of an animal when a choice has to be made is a preference based on the characteristics that normal humans have, and not on the mere fact that they are members of our own species." 35

\section{Tom Regan and the case for animal rights}

In this article, we are dealing with the fate of a single bull. It is sobering therefore, to be confronted with the following shocking statistics in the preface to the 2004 edition of Tom Regan's seminal work "The Case for Animal Rights":

"Forty-eight billion animals are slaughtered annually for food throughout the world. That's more than one hundred and thirty million every day. In excess of five million every hour. Over ninety-one thousand a minute. Some fifteen hundred every second. And these figures do not include the billions of other animals whose lives are taken, whose bodies are injured, and whose freedom is stolen in the name of entertainment, sport, or fashion."

In an article such as this, no more than a brief summary of certain of the main points of Tom Regan's subtle and complex theory of animal rights can be provided. A good place to begin is with the following key passage:

"Some nonhuman animals resemble normal humans in morally relevant ways. In particular, they bring the mystery of a unified psychological presence to the world. Like us, they possess a variety of sensory, cognitive, conative, and volitional capacities. They see and hear, believe and desire, remember and

Since their suffering matters morally, animals that can feel pain must have moral status." (Hills Do Animals Have Rights? 111).

34 Singer Animal Liberation (2002) 20.

35 Singer Animal Liberation (2002) 21.

36 Regan The Case for Animal Rights (2004) xv. This work was first published in 1983. 
anticipate, plan and intend. Moreover, what happens to them matters to them. Physical pleasure and pain - these they share with us. But also fear and contentment, anger and loneliness, frustration and satisfaction, cunning and imprudence. These and a host of other psychological states and dispositions collectively help define the mental life and relative well-being of those (in my terminology) subjects-of-a-life we know better as raccoons and rabbits, beaver and bison, chipmunks and chimpanzees, you and I.",

Regan admits that deciding precisely which animals which may be said to be "subjects-of-a-life" and which not, is difficult if not impossible. ${ }^{38}$ In order to avoid unnecessary argument on this point, he adopts what he calls a "conservative policy", and draws his line at the level "mentally normal mammals of a year or more". ${ }^{39}$ He submits that: "Wherever we draw the relevant line, these animals are above it." ${ }^{40}$

Once the difficulty of drawing the line between those animals (including humans) which are "subjects-of-a-life" and those which are not, is overcome, it is not that big a step to recognize that, due to their similarities, all subjectsof-a-life, both human and non-human, may be said to have "interests", the satisfaction of which promotes their basic welfare (their well-being) and the obstruction of which harms it. As Regan puts it:

"Both animals [by which he means animals which are the subject-of-a-life] and humans have ... interests, some biological, some psychological, some social ... [T]he overall tone or quality of the life of each, to a greater or lesser degree, is a function of the harmonious satisfaction of those preferences that it is in the interests of each to have satisfied ... [T] he same categories of thought (interests, benefits, harms, etc.) that illuminate the most general features of human welfare are equally applicable to animal welfare.

For Regan, it follows that if human welfare is similar in kind to the welfare of animals which are the subject-of-a-life then both must be entitled to a "basic moral right to respectful treatment." ${ }^{\text {"2 }}$ At this point, it is useful to make reference to Regan's concept of "inherent value":

Regan insists that all subjects-of-a-life possess "inherent value". He makes it clear that "inherent value is a categorical concept; an individual either has it, or that individual does not; and all those who have inherent value have this value equally." ${ }^{43}$ Inherent value is not to be confused with individual welfare. An individual (who is the subject-of-a-life) may possess a

37 Regan The Case for Animal Rights (2004) xvi.

${ }^{38} \mathrm{He}$ describes "subjects-of-a-life" as follows: "[l]ndividuals are subjects-of-a-life if they have beliefs and desires; perception, memory, and a sense of the future, including their own future; an emotional life together with feelings of pleasure and pain; preference- and welfareinterests; the ability to initiate action in pursuit of their desires and goals; a psychophysical identity over time; and an individual welfare in the sense that their experiential life fares well or ill for them, logically independently of their utility for others and logically independently of their being the object of anyone else's interests. Those who satisfy the subject-of-a-life criterion themselves have a distinctive kind of value - inherent value - and are not to be viewed or treated as mere receptacles." See Regan The Case for Animal Rights (2004) 248.

39 Regan The Case for Animal Rights (2004) xvi.

40 Ibid.

41 Regan The Case for Animal Rights (2004) xvii.

42 Ibid.

43 Regan The Case for Animal Rights (2004) xxii. 
much poorer quality of life than another individual (who is also the subject-ofa-life), but will still possess precisely the same "inherent value" as that other individual. The inherent value of an individual as the subject-of-a-life must also be distinguished from the value of that individual's life. Inherent value does not differ from one individual to the next (provided that each individual is the subject-of-a-life), but one individual's life may well be more or less valuable than another's. Regan explains this distinction as follows:

"It is a central tenet of the rights view that all subjects-of-a-life have the same kind of value (inherent value) and that they all possess this value equally. However, the value of the life subjects lead needs not be equal, and in many cases, it seems to me, it clearly is not. Recall Frey's [Regan is referring to the philosopher R.G. Frey] example of a very severely mentally enfeebled human. In the rights view's analysis, while the inherent value of subject of this life (Fred, say) is no greater or less than the inherent value of any other subjectof-a-life (Frey, for example), it does not follow that both Fred and Frey have lives that are equal in value. On the contrary, the rights view's analysis implies that the value of a life, like the harm represented by death, increases as the number and variety of possible sources of satisfaction increases. Thus, if it is true, as I believe it is, that Frey's life includes much more by way of possible sources of satisfaction than does Fred's life, then Frey's life has greater value than Fred's."

Let us discuss, in turn, the consequences of adopting each of the abovementioned concepts - the inherent value of each individual subject-ofa-life, on the one hand, and the value of each such individual's life, on the other hand.

Starting with the former of these two concepts, let us examine the implications of the fact that, according to Regan, each individual subject-ofa-life possesses precisely the same inherent value as any other such individual. One of the central principles of Regan's theory - what he calls the "respect principle" - flows from this idea. According to the respect principle "all subjects-of-a-life, both human and nonhuman, share the fundamental right to be treated with respect." ${ }^{45}$ What follows, in turn, from the principle of respect due to each individual subject-of-a-life, is the extremely important conclusion that "no subject-of-a-life may be harmed merely on the grounds that others will benefit." ${ }^{46}$ In an important passage, Regan summarizes his argument, and the implications thereof, as follows:

"The basic moral right to respectful treatment places strict limits on how subjects-of-a-life may be treated. Individuals who possess this right are never

44 Regan The Case for Animal Rights (2004) xxxiv.

45 Regan The Case for Animal Rights (2004) xxvii. Regan maintains that: "[W]e fail to treat individuals who have inherent value with the respect they are due, as a matter of strict justice, whenever we treat them as if they lacked inherent value, and we treat them in this way whenever we treat them as if they were mere receptacles of valuable experiences (e.g., pleasure or preference satisfaction) or as if their value depended upon their utility relative to the interests of others. In particular, therefore, we fail to display proper respect for those who have inherent value whenever we harm them so that we may bring about the best aggregate consequences for everyone affected by the outcome of such treatment ... To borrow part of a phrase from Kant, individuals who have inherent value must never be treated merely as means to securing the best aggregate consequences." See Regan The Case for Animal Rights (2004) 248-249.

46 Regan The Case for Animal Rights (2004) xxvii-xxviii. 
to be treated as if they exist as resources for others; in particular, harms intentionally done to any one subject cannot be justified by aggregating benefits derived by others. In this respect, my position is anti-utilitarian, a theory in the Kantian, not Millian, tradition. But the rights view parts company with Kant when it comes to specifying who should be treated with respect. For Kant, only moral agents exist as ends-in-themselves; only those who are capable of applying abstract, impartial moral principles to their decision making share the equal right to be treated with respect. By contrast, the rights view recognizes the equal inherent value of all subjects-of-a-life, including those who lack the capacities necessary for moral agency. These moral patients (as I call them) have the same equal right to respectful treatment as do moral agents ... [A]lthough I believe that human life contains within it the possibility of a richness not to be found in the life of other animals - because, for example, of our advanced cognitive, aesthetic, moral, and spiritual capacities - this difference provides absolutely no basis whatsoever for our exploitation of other animals.

Having examined the far-reaching implications of the fact that, according to Regan, each individual subject-of-a-life possesses equal "inherent value", let us now turn to the implications of the fact that the life of each such individual will, necessarily, differ in value. This latter fact only becomes relevant in exceptional situations - including what Regan calls "prevention cases" - where a choice has to be made between harm to one or other innocent subject-of-a-life. In other words, life being what it is, situations are bound to arise in which harm to the innocent is inevitable, and hard choices have to be made. For example, consider the case of five survivors of a shipwreck, who are in a lifeboat which will sink unless one of them jumps (or is pushed) overboard. In such an exceptional situation, it becomes necessary to evaluate the lives of the individuals involved, in order to decide who should go overboard. Regan uses the example of "Fred" and "Frey" discussed earlier, and imagines these individuals in a "lifeboat" (that is, an extreme) situation. Regan is clear that, in such an extreme situation, Fred would have to be eased overboard before Frey, since Frey's life is more valuable than Fred's: "In a lifeboat case ... where we had to decide between saving Frey or saving Fred, the right's view verdict, special considerations aside, would be to save Frey." ${ }^{, 48}$ It is very important to note, however, that this only applies in situations which are exceptional. Evaluating lives is only necessary where harm to one or other innocent subject-of-a-life is inevitable and a hard choice has to be made as to which innocent individual is to suffer the harm. Regan expresses this important prerequisite bluntly as follows: "Only in extreme cases would differences in the value of different lives matter." 49

47 Regan The Case for Animal Rights (2004) xvii-xviii. It is important to note that the rights to which Regan is referring attach to individuals. Echoing Ronald Dworkin, at one point, Regan expresses his argument in the following terms: "The obligation to respect the rights of the individual trumps any obligation we might have to promote the social good."

48 Regan The Case for Animal Rights (2004) xxxiv.

49 Ibid. 


\section{Situating the arguments in the present South African context}

Whichever of the above philosophical positions is adopted "anthropocentric" or "non-anthropocentric", "utilitarian" or "anti-utilitarian", "animal welfare" or "animal rights", "Kant" or "Bentham", "Singer" or "Regan" - it is submitted that, when it comes to the deliberate infliction of unnecessary suffering on a sentient animal (such as a bull), the result is the same: there can be no legal or moral justification for such an act within South Africa's present constitutional democracy. Furthermore, when it comes to deciding what constitutes "unnecessary suffering", even what may be regarded as the most conservative of the above philosophical standpoints - that is, anthropocentric views which follow the Kantian tradition - leads to the conclusion that the suffering of an animal (deliberately caused by humans) may only be justified when the most important of human goods is at stake. The less conservative (more forward thinking?) views of Singer and Regan would, of course, set the bar even higher.

Earlier in this section we referred to the possible effects of the particularly South African context in which this debate takes place - that is, that fact that a country whose history is characterized by great cruelty and suffering might be expected to adopt principles designed to move decisively away from practices which cause suffering. Of relevance at this point is the thinking of the South African legal philosopher David Bilchitz, who has put forward a strong argument in favour of the legal personhood and dignity of non-human animals, from a particularly South African perspective. Bilchitz attacks the arbitrary nature of the distinction between human and non-human animals in terms of their legal status and entitlements, and compares this to the arbitrary and unjust nature of the distinctions made during the apartheid period between people artificially classified according to race and according to other arbitrary criteria. He concludes that:

"Arbitrariness, whilst undesirable in itself, also often leads to the disregarding of the interests of individuals, often those who are most vulnerable. However, the new constitutional order was to be formed on the basis of a rejection of arbitrariness and the protection of the fundamental interests of all (particularly those who are most vulnerable): what then should this entail for animals? Clearly, the most desirable route would involve a constitutional amendment, whereby the rights of animals would be explicitly protected directly through the Constitution.

Although it is impossible to trace the subtle and complex argument put forward by Bilchitz, it is clear that his views pose a strong challenge to South Africa's legal thinkers. This is, perhaps, a good point at which to leave the broad "animal rights/animal welfare" side of the debate and to move to the conclusion, in which both sides of the debate need to be assessed.

50 Bilchitz "Moving Beyond Arbitrariness: The Legal Personhood and Dignity of Non-Human Animals" 2009 SAJHR 2566. 


\section{CONCLUSION}

From the range of issues discussed in both the first and second parts of this article, we submit that it is patently clear that there are significantly high stakes involved for both sides in this debate. On the one hand, an ancient ritual shrouded in the mists of time, deeply embedded at the very heart of Zulu culture, at last able to demand the respect due to all diverse cultural practices which form part of the "rainbow nation". On the other hand, a profound concern that the future of South Africa's constitutional democracy not be tainted with the cruelties of the country's tragic past, demanding a decisive rejection of all practices which cause unnecessary suffering to humans or animals. With so much at stake, it seems that the issues discussed in this article are destined to remain the focus of academic and legal debate for the immediate future.

It should be clear from this article that a fundamental dispute of fact exists at the heart of the controversy around the Ukweshwama bull-killing ritual. This dispute of fact centres on whether or not the sacrificial bull is subjected, inevitably, to unnecessary suffering. Those opposed to the ritual will argue that the manner in which the bull is killed (that is, by being wrestled to death by a group of young men), is inherently cruel and, as a matter of course, will result in unnecessary suffering on the part of the sacrificial animal. Those supporting the ritual will argue that, since the bull represents the king himself, the nature of the ceremony dictates that the bull be killed without any unnecessary suffering. It is submitted that this central dispute of fact can only be resolved by expert evidence. What this implies, in turn, is the need for dialogue, to investigate the possibility of opening the ritual to impartial outside scrutiny, in order to establish the facts.

If the facts do show that that the sacrificial bull is exposed to unnecessary suffering, it is submitted that the hurdle to be cleared by those in support of the ritual will be high. Cruelty to animals is not only a violation of South Africa's clear anti-cruelty legislation, but runs completely contrary to the principles of South Africa's constitutional democracy. Cruelty to an animal can only be justified, if at all, where the most fundamental human interests are at stake. As important as certain cultural rituals may be, it is submitted that South African courts will draw the line of legality at the point such rituals may be said to cause unnecessary suffering.

As to the fact that only a single bull is involved in the sacrifice, it is submitted that this should make no difference to the outcome of the debate. If the practice is in fact cruel, it ought to be found to be legally unacceptable. It is submitted that, apart from South Africa's clear legislative ban on any form of cruelty to animals, this country's present constitutional democratic principles simply do not allow for cruelty, whether that cruelty forms part of an important cultural event or not. In fact, the more powerful the cultural symbolism of the event, the more important it is that the event not be tainted by any form of cruelty.

This brings us back to the need for dialogue of a kind which is driven by knowledge of the high stakes and the sensitivities involved on both sides. The extent to which rituals involving animal sacrifice, including the particular 
ritual discussed in this article, are open to investigation from the outside (that is, by neutral and suitably qualified independent experts) must be established. Furthermore, should any forms of animal cruelty be identified within a particular ritual, it must be established whether or not there is scope for discussion about a possible change in the ritual concerned. After all, culture is not static but dynamic. In the same way that a ritual may have changed over time from the sacrifice of a king to the sacrifice of a bull, there may be scope to develop that ritual in such a way as to eliminate any possibility of cruelty. The answer to the question posed in this article - "Is there a place for ancient rituals in the modern world?" - seems to us to be the following (at least in the case of constitutional democracies such as South Africa): "Yes there is, but it may be necessary in certain cases to develop these rituals in such a manner that they accord with developing societal mores, as seen through the lens of the fundamental constitutional values of the country concerned." 